\title{
Interlanguage Pragmatics Theory and Its Implications for Foreign Language
}

\author{
Qian Huang \\ Foreign Language Teaching Department, Dezhou University, Dezhou 253023, China \\ Email:qqh@dzu.edu.cn
}

\begin{abstract}
The major purpose of college English teaching is to cultivate and develop student's pragmatic competence. Interlanguage pragmatics is a new interdisciplinary branch of study based on the theories of pragmatics and second language acquisition which has direct guide significance for foreign language teaching. This paper firstly introduces the theoretical models of the two theories and then focuses on the implications for foreign language teaching.
\end{abstract}

Index Terms - interlanguage pragmatics, pragmatics theory, SLA theory, implications

\section{INTRODUCTION}

In 1969, the psychological linguists Selinker in his paper "Language Transfer" pointed out that when people in different countries and regions have communicate in second Language, language often appears with some native Language and relevant, and with this two kinds of pragmatic styles of Interlanguage totally different, this is "the Interlanguage" (Interlanguage). In Selinker view, the former study of interlanguage study was just the grammar system study. Therefore, the study of interlanguage was only limited from speech phonemes, lexical, syntactic to semantic etc. In the early 1980s, along with deepening the study, the researchers found that only interlanguage study of grammar system is not enough, many problems involving context cannot be solved, pragmatic research and interlanguage study combining produced interlanguage pragmatic. In 1993, the first book on Interlanguage pragmatics gave birth. (Kulka Kasper \& Blum 1993)

Interlanguage Pragmatics theory, the two pillars of the theory of pragmatics and second language acquisition theory are cross-cultural language learning of the study, the Institute of Interlanguage pragmatics of the pragmatic theory based mainly: speech act theory, conversational implicature theory, politeness theory. Kasper and Rose 2002 in the "Second Language Pragmatic Development", a book that two Pragmatics heart can be seen as the process of learning or social practice, Interlanguage pragmatics theory of the system including its five theoretical models: Culture adaptation model theory, cognitive processing model theory, social and cultural theory, language socialization theory and interactive communicative competence model theory. This paper describes research on Interlanguage Pragmatics theoretical models and second language acquisition theory mode, and then explores these theoretical models of the Foreign Language Teaching.

\section{DEVElopment Basis OF INTERLANGUage Pragmatics TheORY}

\section{A. Pragmatics Theory}

1. Speech Act Theory. The theory holds that people use language, the purpose is not only to speak, or express a thought, but by talking to achieve certain goals, that is, words and deeds matter. People to communicate, not only must be good at understanding the speaker's "words in conduct" or "explicit performative" is more important is to understand the speaker's "illocutionary act" or "hidden SHI" and "indirect speech behavior. "

2. Conversational implicature. The theory of discourse on both sides in cooperation with a view to sharing the desire to succeed, based on proposed communication both sides must abide by the true, full, associate, clear the "principle of cooperation." If we say was a breach of the principles of cooperation, then the hearer, who will be in accordance with prevailing context to infer the speaker's true intentions and the discourse of the true meaning.

3. Politeness theory. Courtesy is a national culture and language of a universal phenomenon, which is a verbal communication smooth coordination of the factors. $1983 \mathrm{G}$. Leech will be courtesy of a universal phenomenon as a language to study and put forward the principles of speech communication theory: (1) Tact Maxim (2) generous criteria (3) recognition criterion (4) Modesty Maxim (5) Agreement Maxim (6) Sympathy Maxim Brown \& Levinson put forward the "face theory" that politeness is reflected in the respect of others on the face. Interlanguage Pragmatics by comparing the observed native politeness of those speech acts, reveals the perception of learners as well as the courtesy of the courtesy in the role of cross-cultural communication, and thus more effective guidance to cross-cultural communication.

B. SLA Theory 
1. Cultural adaptation model

The theory by Schumann in the late 20th century, made 70 . He believes that cultural adaptation should be effected from the social environment and individual psychological point of view to explain the motivation in second language acquisition learners and learners in the Pidgin language of the phenomenon. Cultural adaptation that the learners and target language community's social and psychological integration. It consists of two main aspects: social and emotional factors. The former describes the purpose of language learners and the social distance between communities, while the latter seeks to clarify the purpose of language learners and the psychological distance between users. Schumann thinks that two kinds of distance constraints acculturation level and the level of the main reasons for second language acquisition.

2. Cognitive processing model

As early as 90 years in the 20th century, cognitive psychology, the theory was used to explain the pragmatic development, and mainly refers to Schmidt's attention hypothesis and Bialystok's two-dimensional model. Note that assumption concerns the initial stages of learning, stressing conscious concern is that the language input into the key to absorbing the language, so learners through conscious attention to language input to get pragmatic competence. Two-dimensional model is to explain how learners analyze characterization and control along the two dimensions of information processing that have been available in the target language pragmatic knowledge for development. These two theoretical explanations of the different stages of second language learning process, so they are complementary relationships.

3. Multilingual society theory

The theory suggests that learners learned the process of socio-cultural knowledge is the language socialization process, requiring learners to use language to convey his ideas, appropriate and effective. Language socialization process is a lifelong learning process, learners are not in a position of passive acceptance, that is directly beside a professor of social norms, but rather proactive in their daily interactions invisibly learned social norms.

4. Interactive communicative competence model theory.

The theory suggests that communicative competence is in a certain language learners based on the specific communicative context, objects, topic and purpose, using the appropriate conversation skills and communication strategies to carry out interpersonal communication ability. In oral communication, driven by the words and the speaker can be changed according to the different needs of the role of back and forth between the two to replace, that is, possess interpersonal interaction, in which the performance of interactive communication in the communicative competence is called out interactive communicative competence.

\section{Pragmatic TheORY Basis FOR The Foreign LANGUAGE TEACHING}

\section{A. Enhancing Contrast Eastern and Western Cultures to Enhance Cultural Sensitivity}

Language is the carrier of culture. Chinese and Western culture in the way of thinking, values, social and so there are significant differences. Therefore, as a foreign language teacher, first of all, we want to improve their cultural connotations. Second, these cultural differences should be incorporated into the teaching of linguistic knowledge so that students overall understanding of these differences. Particularly vulnerable to misuse for some cases wish to remind, and teach him the correct form. If look at the patient, said: "Drink plenty of water." More: I hope you get better soon. Greeting "Hello, have you had your meal?" Comparison: Hello, a nice day, isn't it? To see them get off "Be careful!" More "Are you ok?" In addition, comparison impresses students deeply and inspires a good memory, for example in the text "There is only luck" the teacher may make a comparison of the law of gun ownership between in China and in America, so that the students can have an awareness of the different background and hence avoid understanding barriers For foreign language teaching, it is only through repeated comparison, in the comparison study, the more learning can enhance the cultural sensitivity, to achieve the purpose of accurate use of language foreign language teaching.

\section{B. Imparting Pragmatic Knowledge to Develop Pragmatic Competence}

At home and abroad interlanguage pragmatics research shows that foreign language learners do not Pragmatic Competence in English language proficiency as students words and sentences capabilities and natural increase. Pragmatics of knowledge should be taught, but also can be taught. Language can help students with knowledge in the form of explicit language and its communicative function is not a-one correspondence, accuracy and appropriateness of discourse to express two aspects of linguistic units to understand the context constrains the choice of the expression of meaning and understanding, and language The "illocutionary force" and the meaning of such sessions.

\section{Add Selective Courses and Bilingual Courses}

The major purpose of college English teaching is to cultivate and develop student's pragmatic competence. To attain appropriate and operational communication, students must have knowledge of the language. "Fully understand a language can be made by insight into that language to the depth and breadth." HeZiRan (1997), so we should add more English selective courses and bilingual courses based on integrated English Course and College English listening Course such as "Contrast study between Chinese and English ", "British \&American Culture and Society", "VOA special English Programs "Cross-cultural Communication ", so as to improve students pragmatic ability. In addition, 
according to the college English Curriculum Requirement "professional English" or "bilingual courses" should be opened as early as possible to develop the students pragmatic ability, so when we they work in the future, they can use English effectively having social interaction both in oral and written English to exchange information.

\section{To "Student-centered" to Enhance Student-teacher Interaction}

Kasper and Rose pointed out that effective classroom interactive activities can promote the learner's language use and communicative capabilities. Therefore, effective classroom interaction is to enhance students' use of language proficiency. Therefore, teachers should adopt a more learner-centered teaching context or communicative approach, and fully mobilize the enthusiasm of students to maximize the first to involve students in learning the entire process.

\section{E. Create a Good Environment for Extra-curricular Language}

Because of certain constraints, China's English learners rarely have the opportunity to directly from the English-speaking environment in the acquisition of language. He certainly would think that: caused by low proficiency in English, is an important reason is that out of context learners to learn English. Therefore, to create a good language learning, the use of environment, especially in extra-curricular communication activities is to develop students ability to use language in an effective way. Teachers should encourage students to more than extra-curricular and foreign professionals to exchange, organized students to see original movies, books, listening to foreign language programs, Taking the natural disaster for example, the teacher may make a video or slide show to display scenes when an earthquake happens, which plays an irreplaceable role in imparting background knowledge and helping students to understand the text easily.

\section{ENDING}

Language teaching can not deviate from the progress of each breakthrough and development of the theory of language, so does the interlanguage pragmatics study. As a new interdisciplinary branch of study based on the theories of pragmatics and second language acquisition, Interlanguage pragmatics is very practical for foreign language teaching, so theoretical model of interlanguage pragmatics will bring about a lot of enlightenment for foreign language teaching.But anyhow it is a new study of this field, how to carry on the further study of its theory and how will be more pragmatic research applied to teaching practice, how to use it the process of teaching and how to further enrich interlanguage pragmatic theories, remain the questions that we language teacher concern.

\section{REFERENCES}

[1] Kasper. G., and Rose, K, R. (2002).Pragmatic Development in a Second Language. Oxford. Blackwell.

[2] Rose, K. \& Kasper, G. (2001). Pragmatics in Language Teaching. Cambridge: Cambridge University Press.

[3] G. Leech. (1983). Principles of Pragmatics. London and New York: Longman. Levinson, Stephen.

[4] Zhiran He, Xinren Chen. (2004).Contemporary Pragmatics. Beijing: Foreign Language Education and Research Press.

[5] Zhian Cheng, Yuanquan Yuan. (2001). Review and Prospect of the Study of Intelanguage Research. Foreign Language Teaching.

[6] Zhaoxiong He. (2000).New Outline of Pragmatics. Shanghai: Shanghai Foreign Language Education Press.

[7] Gang Hong. (1991). Survey on English pragmatics and its implication for Foreign Language Teaching. Foreign Language Teaching and Research, 3.

[8] Barron, A. (2003). Acquisition in Interlanguage Pragmatics: Learning how to Do Things with Words in a Study Abroad Context. Amsterdam: John Benjamins Publishing Company.

Qian Huang was born in Hangzhou, China in 1966. She received her M.A. degree in history from Shandong University, China. She is currently an associate professor in the Department of Foreign Language teaching, Dezhou University, Shandong, China. Her research interests include linguistics and American literature. 